\title{
Recent Research Advances in Upper-extremity Rehabilitation
}

\section{Furui Wang ${ }^{\star}$}

Abbott Laboratories, Princeton, USA

Upper extremity impairment is a prevalent outcome for a variety of neuromuscular disorders, such as stroke. According to the American Stroke Association, each year about 795,000 Americans experience a new or recurrent stroke; i.e., every 40 seconds in the United States, someone suffers a stroke [1]. $60-75 \%$ of these patients will live beyond one year after the incidence, resulting in an estimated stroke population of 7 million in the USA alone [1-3]. Upper-extremity function is acutely impaired in a large majority of those diagnosed with stroke [4-7]. Furthermore, acute hemiparesis presages chronic hemiparesis in over $40 \%$ of individuals $[5,6]$ suffering from stroke. Chronic deficits are prevalent in the distal upper extremities, especially with regard to arm and hand motor function. Intensive physical therapies help patients regain useful functions of upper extremities, help with activities of daily living, and make them more independent.

Clinical results have indicated that movement assisted therapy can have a significant beneficial impact on a large segment of the population affected by stroke. In recent years, new techniques adopting a task-oriented approach have been developed to encourage active training of the affected limb, which assume that control of movement is organized around goal-directed functional tasks [8,9]. "Shaping" is one of the task oriented behavioral training techniques employed in Constraint-Induced Movement (CI) therapy [8-10], which has the effect of placing optimal adaptive task practice procedures into a systematic, standardized and quantified format. The availability of such training techniques, however, is limited by the amount of costly therapist's time they involve, and the ability of the therapist to provide controlled, quantifiable and repeatable assistance to complex arm and hand motion.

Consequently, robot assisted rehabilitation could be used to automate labor-intensive training technique, to provide programmable levels of assistance to the patients, to quantitatively monitor and adapt to the patient's progress during rehabilitation, in a more cost-efficient manner. Robot-assisted physical rehabilitation has been an active research area in recent years to assist, enhance and quantify rehabilitation. The robotassisted therapies provide autonomous training where patients are engaged in repeated and intense practice of goal directed tasks leading to improvements in motor function. Robotic rehabilitation devices and systems are being developed to automate therapy for the arm, wrist and hand following stroke. The MIT-Manus (Massachusetts Institute of Technology Manus) [11,12], Assisted Rehabilitation and Measurement (ARM) Guide [13,14], Mirror Image Movement Enabler (MIME) [1517] and GENTLE/s [18] are developed to facilitate the arm movement of stroke patients. Robotic devices designed for wrist rehabilitation has been reported in [19-21]. A number of devices have been developed expressly for or applied to hand rehabilitation. These include both commercial products, such as CyberGrasp (Immersion Corporation, San Jose, CA) [22], the Hand Mentor (Kinetic Muscles Inc., Tempe, AZ) [23], and the Amadeo Hand System (Tyromotion GmbH, Graz, Austria) [24]. Experimental devices include Rutgers Master II-ND [25], HWARD [26] and HandCARE [27] among others [28-31].

The promising results of the above mentioned rehabilitation robotic systems indicate that the robots could be used as effective rehabilitation tools. However, the question regarding the best use of these robotic systems for rehabilitation remains. The extent to which rehabilitation robots should assist, resist, or otherwise alter movement of the user is still unclear. This is a key area where progress needs to be made for rehabilitation robotics.

Those with the most success to date tend to focus on intense and repetitive practice of the affected limb with cognitive processing as a means for motor program reorganization, during which patients not only make repetitive movement but also pay attention to tracking accuracy. However, the patients may not be able to track the desired motion because of their impairments during the task execution. Thus, robotic assistance is provided to help the patients complete the task in different manners. Several strategies have been developed, including passive [32,33], active-assistance [13,14,19,32-35], active-constrained [33], counterpoise control [36], resistive [35], error-amplifying [36$39]$, and bimanual modes $[33,40,41]$. The primary strategies tested so far is active assistance [13,14,19,32-35], a clinical term that refers to exercises in which the patient attempts a movement (active) and in which a therapist manually helps complete the movement if the patient is unable (assistance) [42]. It has been suggested that in robotassisted rehabilitation, assisting every movement of a patient is not as beneficial compared to assistance as needed [43]. Performance-based therapies have showed better results in improving patients' impairment scores than conventional therapies $[13,14,44]$. Meanwhile, research has demonstrated that movement tracking training that requires cognitive processing achieved greater gains in performance than that of movement training that did not require cognitive processing [45]. Many models and artificial learning systems such as neural networks suggest that error drives sensorimotor learning of a person, so that one can learn adaptation more quickly if the error is augmented to a certain degree [46]. Such error-driven learning processes are believed to be central to adaptation and the acquisition of skill in human movement $[44,47]$. It has been shown that visual error augmentation can improve the rate and extent of motor learning in healthy participants [38] and elicit functional improvements in patients with chronic stroke and traumatic brain injury [39]. Incorporating visual feedback and visual error augmentation strategy with active robotic assistance has the potential to improve the efficiency in robot-assisted rehabilitation training [48].

In recent years, advanced robotic systems are developed aiming for the upper-extremities rehabilitation, including upper-limb, wrist and hand. Rehabilitation strategies are investigated to make the best use of these robotic systems. Rehabilitation robotics has become an

*Corresponding author: Furui Wang, Systems Engineer, Abbott Laboratories, Princeton, USA, E-mail: furui.wang@gmail.com

Received August 03, 2012; Accepted August 06, 2012; Published August 08, 2012

Citation: Wang F (2012) Recent Research Advances in Upper-extremity Rehabilitation. Adv Robot Autom 1:e110. doi:10.4172/2168-9695.1000e110

Copyright: (c) 2012 Wang F. This is an open-access article distributed under the terms of the Creative Commons Attribution License, which permits unrestricted use, distribution, and reproduction in any medium, provided the original author and source are credited. 
important topic in robotics research. With the continuous progress in rehabilitation robotics research, it is reasonable to believe that robotassisted rehabilitation systems will greatly improve the efficiency and reduces the cost of rehabilitation, and benefit patients with motor disabilities.

\section{Reference}

1. American Heart Association (2012) Heart and Stroke Statistics Update.

2. Bonita R, Stewart A, Beaglehole R (1990) International trends in stroke mortality: 1970-1985. Stroke 21: 989-992.

3. Broderick JP, Phillips SJ, Whisnant JP, O'Fallon WM, Bergstralh EJ (1989) Incidence rates of stroke in the eighties: the end of the decline in stroke? Stroke 20: $577-582$

4. Gray CS, French JM, Bates D, Cartlidge NEF, James OFW, et al. (1990) Motor Recovery Following Acute Stroke. Age Ageing 19: 179-184.

5. Nakayama H, Jørgensen HS, Raaschou HO, Olsen TS (1994) Recovery of upper extremity function in stroke patients: the Copenhagen Stroke Study. Arch Phys Med Rehabil 75: 394-398.

6. Parker VM, Wade DT, Langton Hewer R (1986) Loss of arm function after stroke: measurement, frequency, and recovery. Int Rehabil Med 8: 69-73.

7. Radomski MV, Trombly CA (2008) Occupational therapy for physical dysfunction (6thedn): Williams \& Wilkins, Baltimore, MD.

8. Taub E, Miller NE, Novack TA, Cook EW 3rd, Fleming WC, et al. (1993) Technique to improve chronic motor deficit after stroke. Arch Phys Med Rehabi 74: $347-354$.

9. Volpe BT (2004) "Stroke, stroke": a coxswain's call for more work and more innovation. J Rehabil Res Dev 41: 7-10

10. Taub E, Uswatte G, Pidikiti R (1999) Constraint-Induced Movement Therapy: a new family of techniques with broad application to physical rehabilitation--a clinical review. J Rehabil Res Dev 36: 237-251

11. Krebs HI, Palazzolo JJ, Dipietro L, Ferraro M, Krol J, et al. (2003) Rehabilitation Robotics: Performance-Based Progressive Robot-Assisted Therapy. Autonomous Robots 15: 7-20.

12. Krebs HI, Ferraro M, Buerger SP, Newbery MJ, Makiyama A, et al. (2004) Rehabilitation robotics: pilot trial of a spatial extension for MIT-Manus. J Neuroengineering Rehabil 1: 5.

13. Kahn LE, Zygman M, Rymer W, Reinkensmeyer DJ (2006) Robot-assisted reaching exercise promotes arm movement recovery in chronic hemiparetic stroke: a randomized controlled pilot study. J Neuroengineering Rehabil 3: 12.

14. Kahn LE, Lum PS, Rymer WZ, Reinkensmeyer DJ (2006) Robot-assisted movement training for the stroke-impaired arm: Does it matter what the robot does? J Rehabil Res Dev 43: 619-630.

15. Lum PS, Burgar CG, Kenney DE, Van der Loos HF (1999) Quantification of force abnormalities during passive and active-assisted upper-limb reaching movements in post-stroke hemiparesis. IEEE Trans Biomed Eng 46: 652-662.

16. Burgar CG, Lum PS, Shor PC, Machiel Van der Loos HF (2000) Development of robots for rehabilitation therapy: the Palo Alto VA/Stanford experience. J Rehabil Res Dev 37: 663-673.

17. Lum PS, Burgar CG, Van der Loos M, Shor PC, Majmundar M, et al. (2006) MIME robotic device for upper-limb neurorehabilitation in subacute stroke subjects: A follow-up study. J Rehabil Res Dev 43: 631-642.

18. Loureiro R, Amirabdollahian F, Topping M, Driessen B, Harwin W (2003) Upper Limb Robot Mediated Stroke Therapyâ GENTLE/s Approach. Autonomous Robots 15: 35-51.

19. Hesse S, Schulte-Tigges G, Konrad M, Bardeleben A, Werner C (2003) Robotassisted arm trainer for the passive and active practice of bilateral forearm and wrist movements in hemiparetic subjects. Arch Phys Med Rehabil 84: 915-920.

20. Charles SK, Krebs HI, Volpe BT, Lynch D, Hogan N (2005) Wrist rehabilitation following stroke: initial clinical results. 13-16.

21. Gupta A, O'Malley MK, Patoglu V, Burgar C (2008) Design, Control and Performance of RiceWrist: A Force Feedback Wrist Exoskeleton for Rehabilitation and Training. Int J Rob Res 27: 233-251.
22. Adamovich SV, Fluet GG, Mathai A, Qiu Q, Lewis J, et al. (2009) Design of a complex virtual reality simulation to train finger motion for persons with hemiparesis: a proof of concept study. J Neuroeng Rehabil 6: 28.

23. Kinetic Muscles Inc., Hand Mentor.

24. Tyromotion $\mathrm{GmbH}$, Amadeo Hand System.

25. Jack D, Boian R, Merians AS, Tremaine M, Burdea GC, et al. (2001) Virtual reality-enhanced stroke rehabilitation. IEEE Trans Neural Syst Rehabil Eng 9 : 308-318.

26. Takahashi CD, Der-Yeghiaian L, Le V, Motiwala RR, Cramer SC (2007) Robotbased hand motor therapy after stroke. Brain 131: 425-437.

27. Dovat L, Lambercy O, Gassert R, Maeder T, Milner T, et al. (2008) HandCARE: a Cable-Actuated Rehabilitation System to Train Hand Function After Stroke. IEEE Trans Neural Syst Rehabil Eng 16: 582-591.

28. Jones CL, Furui W, Osswald C, Xuan K, Sarkar N, et al. (2010) Control and kinematic performance analysis of an Actuated Finger Exoskeleton for hand rehabilitation following stroke. 3rd IEEE RAS and EMBS International Conference on Biomedical Robotics and Biomechatronics (BioRob)

29. Wege A, Hommel G (2005) Development and control of a hand exoskeleton for rehabilitation of hand injuries. Intelligent Robots and Systems, IEEE/RS International Conference 3046-3051.

30. DiCicco M, Lucas L, Matsuoka Y (2004) Comparison of control strategies for an EMG controlled orthotic exoskeleton for the hand. Robotics and Automation, Proceedings. ICRA ‘04, 2004 IEEE International Conference 2: 1622-1627.

31. Kawasaki H, Ito S, Ishigure $\mathrm{Y}$, Nishimoto $\mathrm{Y}$, Aoki T et al. (2007) Development of a Hand Motion Assist Robot for Rehabilitation Therapy by Patient SelfMotion Control. Rehabilitation Robotics, ICORR 2007, IEEE 10th International Conference 234-240.

32. Volpe BT, Krebs HI, Hogan N, Edelstein OTR L, Diels C, et al. (2000) A novel approach to stroke rehabilitation: robot-aided sensorimotor stimulation Neurology 54: 1938-1944.

33. Lum PS, Burgar CG, Shor PC, Majmundar M, Van der Loos M (2002) Robotassisted movement training compared with conventional therapy techniques for the rehabilitation of upper-limb motor function after stroke. Arch Phys Med Rehabil 83: 952-959.

34. Kahn LE, Zygman ML, Rymer WZ, Reinkensmeyer DJ (2001) Effect O Robot-Assisted And Unassisted Exercise On Functional Reaching In Chronic Hemiparesis. 2: 1344-1347.

35. Fasoli SE, Krebs HI, Stein J, Frontera WR, Hogan N (2003) Effects of robotic therapy on motor impairment and recovery in chronic stroke. Arch Phys Med Rehabil 84: 477-482.

36. Patton JL, Mussa-Ivaldi FA, Rymer WZ (2001) Altering movement patterns in healthy and brain-injured subjects via custom designed robotic forces. 2: 13561359.

37. Brewer BR, Klatzky R, Matsuoka Y (2004) Effects of visual feedback distortion for the elderly and the motor-impaired in a robotic rehabilitation environment Robotics and Automation, Proceedings. ICRA 04', 2004 IEEE International Conference 2: 2080-2085

38. Wei Y, Bajaj P, Scheidt R, Patton J (2005) Visual error augmentation for enhancing motor learning and rehabilitative relearning. Rehabilitation Robotics, ICORR $9^{\text {th }}$ International Conference 505-510.

39. Wang F, Barkana DE, Sarkar N (2009) Evaluation of a robot-assisted rehabilitation system with assist-as-needed and visual error augmentation training methods. Intelligent Robots and Systems, IROS 2009, IEEE/RSJ International Conference 3555-3560.

40. Lum SP, Lehman SL, Reinkensmeyer DJ (1995) The bimanual lifting rehabilitator: an adaptive machine for therapy of stroke patients. IEEE Trans Rehabil Eng 3: 166-174.

41. Lum PS, Reinkensmeyer DJ, Lehman SL (1993) Robotic assist devices fo bimanual physical therapy: preliminary experiments. IEEE Trans Rehabil Eng 1: 185-191.

42. Reinkensmeyer DJ, Emken JL, Cramer SC (2004) Robotics, Motor Learning And Neurologic Recovery. Annu Rev Biomed Eng 6: 497-525. 
43. Reinkensmeyer DJ (2003) How to retrain movement after neurologic injury: a computational rationale for incorporating robot (or therapist) assistance. Engineering in Medicine and Biology Society, Proceedings of the $25^{\text {th }}$ Annual International Conference of the IEEE 2: 1479-1482.

44. Kawato M (1990) Feedback-Error-Learning Neural Network for Supervised Motor Learning. Advanced Neural Computers 365-372.

45. Carey JR, Bhatt E, Nagpal A (2005) Neuroplasticity Promoted by Task Complexity. Exerc Sport Sci Rev 33: 24-31.
46. Rumelhart DE, Hinton GE, Williams RJ (1986) Learning representations by back-propagating errors. Nature 323: 533-536.

47. Wolpert DM, Ghahramani Z, Jordan MI (1995) An internal model for sensorimotor integration. Science 269: 1880-1882.

48. Wang F, Barkana DE, Sarkar N (2010) Impact of Visual Error Augmentation When Integrated With Assist-as-Needed Training Method in Robot-Assisted Rehabilitation. IEEE Trans Neural Syst Rehabil Eng 18: 571-579. 